\title{
BENDING STRENGTH OF HYBRID COMPOSITE OF GLASS AND NATURAL FIBER PHINEAGE LEAVES
}

\author{
Muhammad Fachnoor Latuconsina ${ }^{1}$, Istyawan Priyahapsara ${ }^{2}$ \\ Teknik Dirgantara, Institut Teknologi Dirgantara Adisutjipto \\ fachnoorlatuconsina@gmail.com ${ }^{1}$, istyawanpriyahapsara@gmail.com²
}

\begin{abstract}
The development of composite fibers has developed very much, and to reduce the environmental impact, composite fibers use natural fiber alternatives. The development of composite fibers has developed very much, and to reduce the environmental impact, composite fibers use natural fiber alternatives. One of the natural fibers that are commonly used is natural fiber from pineapple leaves, where natural fiber from ananas leaves is still very minimal in its commercial use and is only considered as waste.
\end{abstract}

Keywords: composite, fiber and environmental

\section{Pendahuluan}

Material komposit sudah sangat berkembang sangat pesat di dunia rekayasa dewasa ini. Komposit sendiri di manfaatkan sudah semakin luas di pasar industri, seperti di gunakan untuk mengganti logam karena cenderung lebih kuat di bandingkan logam dengan masa yang sama. Salah satu pemanfaatan komposit adalah dengan menggabungkan dua atau lebih komponen komposit berbeda agar dapat mengisi kekurangan satu sama lain atau sering di sebut dengan komposit Hybrid [ ${ }^{1][2] \text {. }}$

Komposit Hybrid yang merupakan gabungan dari beberapa lapisan yang searah (unidrectional) yang disusun dengan jumlah dan urutan tertentu (Nurun Nayiroh, 2013). salah satu tipe komposit Hybrid yang sangat potensial adalah komposit lamina Hybrid, karena komposit lamina Hybrid sediri merupakan komposit yang dapat menggabungkan beberapa serat penguat dengan beberapa lapis yang dapat di variasikan dengan sangat luas baik dari sisi arah sudut, ragam serat, dan lain sebagainya. Keragaman ini yang membuat komposit Hybrid lamina masih dapat di explorasi lebih jauh dengan melakukan pengujian lebih lanjut ${ }^{[3] \text {. }}$

Pengembangan serat komposit sudah sangat banyak berkembang, dan untuk mengurangi dampak lingkungan hidup maka serat komposit mengunakan alternatif serat alami. Pengembangan serat komposit sudah sangat banyak berkembang, dan untuk mengurangi dampak lingkungan hidup maka serat komposit mengunakan alternatif serat alami. Salah satu serat alam yang umum di gunakan adalah serat alam daun nanas, di mana serat alam daun ananas ini masih sangat minim penggunannya secara komersial hanya di anggap sebagai limbah. Suatu penelitian menunjukkan bahwa serat daun nanas memiliki kekuatan tarik hampir dua kali lebih tinggi dibandingkan dengan fiberglass. Serat daun nanas memiliki kekuatan tarik sebesar $42,33 \mathrm{~kg} / \mathrm{mm}^{2}$, sedangkan fiberglass mempunyai kekuatan tarik sebesar $21,65 \mathrm{~kg} / \mathrm{mm}^{2}$. Oleh sebab itu, serat daun nanas memiliki potensi untuk digunakan sebagai pengisi dalam suatu komposit. Dari pembahasan diatas maka penelitian ini mengacu pada pembuatan komposit lamina Hybrid berpenguat serat alam daun nanas dan fiberglass bermatrik epoxy yang diperuntukan untuk mendapatkan data pengaruh arah sudut serat daun nanas terhadap kekuatan bending sesuai standar yang telah di tentukan sebelumnya ${ }^{[4][5][6] \text {. }}$

\section{Metode Penelitian}

Metode studi literatur merupakan suatu metode pengambilan data yang dilakukan oleh penulis dari berbagai sumber media cetak maupun media elektronik, yang berkaitan dengan penelitian yang dilakukan oleh penulis. 
Sumber literatur yang digunakan diantara lain:

a. Literatur Pengumpulan data berdasarkan dari sumber media cetak, jurnal, penelitian sebelumnya yang relevan dengan penelitian mengenai komposit, pengaruh arah serat terhadap sifat mekanik komposit, dan pengujian bending.

b. Internet, Pengumpulan data berasal dari website dan situs yang digunakan dalam menguatkan hasil dari penelitian. Metode ini dapat membantu pembaca dalam memahami pemikiran penulis melalui gambar-gambar yang didapat dari internet

Analisis data adalah proses yang dilakukan dengan penyusunan data yang telah didapatkan agar mudah dipahami melalui pendekatan-pendekatan tersendiri sehingga dapat mendapatkan output yang akurat dan valid kebenarannya. Data-data tersebut diperoleh dari hasil pengamatan serta observasi literatur maupun melakukan wawancara sehingga dapat menghasilkan sebuah data deskripsi yang valid. Metode pengumpulan data yang diperlukan untuk memecahan masalah yang timbul berdasarkan fokus penelitian ${ }^{[7]}$. Data-data diperoleh menggunakan dua metode, yaitu:

a. Metode wawancara, yaitu metode mengumpulkan data dan informasi terkait dengan penelitian yang akan dilakukan dengan cara bertanya langsung kepada narasumber yang berkompeten dalam bidang material komposit baik itu dosen, laboratorium tempat melakukan penelitian dan lain sebagainya.

b. Metode studi pustaka, yaitu metode pengumpulan data dengan membaca buku, artikel atau jurnal penelitian yang telah dilakukan sebelumnya.

Metode observasi, yaitu metode mengumpulkan data dengan pelitian langsung terhadap spesimen uji komposit Hybrid serat kaca dan serat daun nanas dengan variasi sudut kemudian di uji kekuatan bending. Dalam penelitian yang akan dilakukan, objek yang menjadi sasaran penelitian yaitu komposit Hybrid serat kaca dan serat daun nanas yang di buat dengan metoden hand lay-up. Hasil dalam penelitian ini berupa sebuah data analisis kekuatan bending masing masing spesimen dengan variasi arah sudut serat alam daun nanas $0^{\circ} .45^{\circ} .90^{\circ[8][9][10] .}$

\section{Hasil Dan Analisis}

Tahap pertama dalam pembuatan komposit adalah membuat cetakan dari kaca yang di susun dengan ukuran cetakan 20x12x0,5 $\mathrm{cm}^{3}$ dimana kaca yang di butuhkan dengan tebal 5 $\mathrm{mm}$, dengan ukuran $30 \times 30 \mathrm{~cm}$ sebagai alas dan penutup, 24x2 cm untuk cetakan panjang dan $12 \times 2 \mathrm{~cm}$ untuk lebar komposit. berikut tahap pembuatan cetakan :

a. Membersihkan kaca

Pembersihan kaca di maksudnkan agar cetakan kaca tidak terkontaminasi dan bersih dari kotoran yang mampu mempengaruhi komposit, pembersihan kaca in di lakukan dengan cairan thiner yang di tuangkan pada permukaan kaca kemudian kaca di lap hingga bersih.

b. Pelapisan Wax

Pelapisan Wax di maksudkan untuk melapisi kaca agar resin atau matrik tidak bersentuhan langsung dengan kaca dan tidak lengket sehingga dapat di lepaskan dengan mudah. Pelapisan di lakukan dengan cara meratakan Wax ke kaca kemudian keringkan selams 1015 menit kemudian di bersihkan dengan lap dan di lapisi sekali lagi, proses ini akan berukang hingga lapisan tipis $\operatorname{Wax}$.

c. Penyusunan kaca

Setelah kaca di lapisi dengan Wax kaca akan dilakukan pembentukan komposit dengan cara menyatukan kaca menggunakan lem sedemikian rupa hingga membentuk cetakan dengan ukuran $20 \times 12 \times 0,5 \mathrm{~cm}$. 
d. Penyumbatan celah kaca

Setelah cetakan terbentuk langkah selanjutnya adalah melapisi daerah sudut dan cela cetakan dengan lilin basah, pelapisan dimaksudkan untuk mencegah keluarnya matrik dari sela-sela kaca.

Penentuan fraksi volume ini di maksudkan agar komposit yang di uji setiap spesimen harus dengan komposisi yang sama dalam serat dan matrik agar tidak mempengaruhi hasil uji berikut tahap penentuan fraksi volume penentuan fraksi volume adalah

- Menghitung volume cetakan dimana cetakan komposit berukuran $20 \times 12 \times 0,5 \mathrm{~cm}^{3}$ maka di tentukan volume cetkan dengan rumus :

$$
V_{\text {cetakan }}=P \times L \times t=20 \mathrm{~cm} \times 12 \mathrm{~cm} \times 0.5 \mathrm{~cm}=120 \mathrm{~cm}^{3}
$$

- $\quad$ Menghitung kebutuhan Fiber Glass

1) Hal yang pertama di lakukan adalah dengan memotong Woven fiber glas menyesuaikan benutk cetakan dengan ukuran 20x12

2) Menimbang massa fiber yang telah di potong sesuai ukuran cetakan maka di dapat $\mathrm{M}_{\text {serat kaca }}=12$ gram di kali dua Layer sesuai kebutuhan Layer Fiber Glass maka di dapatkan rumus

$M_{\text {total kaca }}=M_{\text {serat kaca }} \times 2$ layer

$M_{\text {total kaca }}=12 \times 2$ layer

$M_{\text {total kaca }}=24$

Maka di dapat kebutuhan serat kaca total untuk dua Layer adalah 24 gram

3) Menghitung volume serat kaca di tentukaan dengan rumus

Dik : $\rho_{\text {kaca }}=2,55 \frac{\mathrm{gr}}{\mathrm{cm}^{3}}$ (Nurun Nayiroh, 2013)

$V_{\text {kaca }}=\frac{M_{\text {total kaca }}}{\rho_{\text {kaca }}}$

$V_{k a c a}=\frac{24 \mathrm{gr}}{2,55 \mathrm{gr} / \mathrm{cm}^{3}}$

$V_{\text {kaca }}=9,411 \mathrm{~cm}^{3}$

4) Menghitung fraksi volume serat kacadi tentukan dengan rumus

fraksi volume kaca $=\frac{V_{\text {kaca }}}{V_{\text {cetakan }}} \times 100 \%$

fraksi volume kaca $=\frac{9,411}{120} \times 100 \%$

fraksi volume kaca $=7,842 \%$

- Menghitung kebutuhan serat daun nanas

a) Hal yang pertama di lakukan adalah dengan memotong serat alam daun nanas menyesuaikan bentuk cetakan dengan bentuk arah serat sesuai variasi $0^{\circ}, 45^{\circ}, 90^{\circ}$.

b) Sert yang sudah di bentuk kemudian di timbang untuk mendapat massa serat yang di butuhkan atau $M_{\text {daun nanas }}$ di mana unntuk serat alam daun nanas yang dibutuhkan hanya satu Layer maka di dapat 11 gram.

c) Menghitung volume serat daun nanas di tentukaan dengan rumus

Dik : $\rho_{\text {daun nanas }}=1,072 \frac{\mathrm{gr}}{\mathrm{cm}^{3}}$ (Sumber: Silvia, 2015)

$V_{\text {daun nanas }}=\frac{M_{\text {serat }}}{\rho_{\text {daun nanas }}}$

$V_{\text {daun nanas }}=\frac{11 \mathrm{gr}}{1,072 \mathrm{gr} / \mathrm{cm}^{3}}$

$V_{\text {daun nanas }}=10.261 \mathrm{~cm}^{3}$ 
d) Menghitung fraksi volume serat kacadi tentukan dengan rumus

fraksi daun nanas $=\frac{V_{\text {daun nanas }}}{V_{\text {cetakan }}} \times 100 \%$

fraksi daun nanas $=\frac{10.261}{120} \times 100 \%$

fraksi daun nanas $=8.55 \%$

Maka di tentukan fraksi volume serat daun nanas adalah $8.55 \%$ yang di butuhkan dalam pencetakan komposit Hybrid serat kaca dan serat daun nanas.

- Menghitung kebutuhan matrik

a. $V_{\text {metriks }}=V_{\text {cetakan }}-V_{\text {Komposit }}$

$V_{\text {komposit }}=V_{\text {kaca }}+V_{\text {daun nanas }}$

$V_{\text {komposit }}=9,411 \mathrm{~cm}^{3}+10,261 \mathrm{~cm}^{3}$ maka $V_{\text {komposit }}=19,672 \mathrm{~cm}^{3}$

Maka di dapat:

$V_{\text {metriks }}=V_{\text {cetakan }}-V_{\text {Kom }}$ maka $V_{\text {metriks }}=120 \mathrm{~cm}^{3}-19,672 \mathrm{~cm}^{3}$

$V_{\text {metriks }}=100,328 \mathrm{~cm}^{3}$

Dimana matrik yang di gunakan adalah epoxy A B maka di perlukan perhitungan volume epoxy dan volume epoxy hardener demngan perbandingan epoxy dan hardener adalah 2:1 maka di tentukan kebutuhannya dengan rumus :

1) epoxy

$$
\begin{aligned}
& V_{\text {epoxy }}=\frac{2}{3} \times V_{\text {metriks }} \\
& V_{\text {epoxy }}=\frac{2}{3} \times 100,328 \mathrm{~cm}^{3} \\
& V_{\text {epoxy }}=66.885 \mathrm{~cm}^{3}
\end{aligned}
$$

Maka kebutuhan berat epoxy yang di butuhkan dapat di tentukan dengan rumus :

Dik : $\rho_{\text {epoxy }}=1,17 \frac{\mathrm{gr}}{\mathrm{cm}^{3}}$ (Nurun Nayiroh, 2013)

$$
\begin{aligned}
& M_{\text {epoxy }}=V_{\text {epoxy }} \times \rho_{\text {epoxy }} \\
& M_{\text {epoxy }}=66.885 \mathrm{~cm}^{3} \times 1,17 \frac{\mathrm{gr}}{\mathrm{cm}^{3}} \\
& M_{\text {epoxy }}=78.255 \mathrm{gr}
\end{aligned}
$$

2) hardener

$$
\begin{aligned}
V_{\text {hardener }} & =\frac{1}{3} \times V_{\text {metriks }} \\
V_{\text {hardener }} & =\frac{1}{3} \times 100,328 \mathrm{~cm}^{3} \\
V_{\text {hardener }} & =33.442 \mathrm{~cm}^{3}
\end{aligned}
$$

Maka kebutuhan berat hardener yang di butuhkan dapat di tentukan dengan rumus :

Dik : $\rho_{\text {hardener }}=0,963 \frac{\mathrm{gr}}{\mathrm{cm}^{3}}$ (Nurun Nayiroh, 2013)

$$
\begin{aligned}
& M_{\text {hardener }}=V_{\text {hardener }} \times \rho_{\text {hardener }} \\
& M_{\text {total kaca }}=33.442 \mathrm{~cm}^{3} \times 0,963 \frac{\mathrm{gr}}{\mathrm{cm}^{3}} \\
& M_{\text {total kaca }}=32.204 \mathrm{gr}
\end{aligned}
$$

Maka di dapatkan di tentukan bahwa volume matrik yang di butuhkan adalah 
b. menentukan fraksi volume matrik dengan menggunakan rumus :

$$
\begin{aligned}
& \text { fraksi volume metriks }=\frac{V_{\text {metriks }}}{V_{\text {cetakan }}} \times 100 \% \\
& \text { fraksi volume metriks }=\frac{100,328}{120} \times 100 \% \\
& \text { fraksi volume metriks }=83,606 \% \\
& \text { Dengan komposisi epoxy dan hardener sebagai berikut }
\end{aligned}
$$$$
\text { 1) epoxy }
$$$$
\text { fraksi volume epoxy }=\frac{V_{\text {epoxy }}}{V_{\text {cetakan }}} \times 100 \%
$$$$
\text { fraksi volume epoxy }=\frac{66.885}{120} \times 100 \%
$$$$
\text { fraksi volume epoxy }=55,737 \%
$$

2) hardener

fraksi volume hardener $=\frac{V_{\text {hardener }}}{V_{\text {cetakan }}} \times 100 \%$

fraksi volume hardener $=\frac{33.442}{120} \times 100 \%$

fraksi volume hardener $=27,868 \%$

Dengan mengetahui perhitungan di atas maka di tentukan fraksi volume serat kaca adalah 7,842\%, serat alam daun nanas adalah 8.55\% dam Matrik adalah 83,66 \% dengan komposisi epoxy dan hardener adalah 55,737\% untuk epoxy dan 27,868 \% untuk hardener dengan perbandingan 2:1 dalam pencetakan komposit Hybrid serat kaca dan serat daun nanas. Tahap selanjutnya adalah penyatuan serat dan matrik tahap ini bermaksud mengikat serat sehingga menjadi kesatuan komposit dimana pada komposit ini membutuhkan 3 Layer. berikut tahapan penyusunan komposit :

a. Menyusun Layer pertama serat Woven kaca kemudian di ratakan dengan matrik sampai

Layer pertama basah dengan matrik, kemudian serat daun nanas pada Layer kedua disusun sesuai variasi arah sudut yang di tentukan $0^{\circ}, 45^{\circ}, 90^{\circ}$ kemudian di lapisi lagi dengan matrik hingga merata dan di timpa lagi dengan serat kaca Layer ketiga dan di ratakan dengan matrik hingga benar merata .

b. Langkah kedua menutup cetakan dengan kaca dan di timpa beban hingga 24 jam hingga matrik mengering merata .

c. Bongkar cetakan kemudian mengeluarkan kopomposit Hybrid serat kaca dan serat daun nanas yang sudah terbentuk kemudian di finishing dari kotoran dan sisi yang kelebihan

Setelah melakukan pembuatan Komposit Hybrid kaca dan serat alam daun nanas dengan variasi yang telah di tentukan maka komposit tersebut akan dilakukan pembentukan berdasarkan $A S T M$ dimana ukuran spesimen uji dengan panjang $20 \mathrm{~cm}$, lebar $2 \mathrm{~cm}$, dengan tebal spesimen $0,5 \mathrm{~cm}$. Komposit ini akan dipotong menggunakan gergaji besi sesuai arah komposit yang sudah di tentukan.Pada penelitian ini, dilakukan pengujian bening pada komposit Hybrid serat kaca dan serat daun nanas dengan beberapa spesimen yaitu komposit Hybrid serat kaca dan serat daun nanas dengan arah sudut variasi $0^{\circ}, 45^{\circ}, 90^{\circ}$. Bentuk spesimen yang dilakukan pengujian bending telah disesuai dengan $A S T M \quad D 790$. Dalam pengujian bending ini, spesimen dengan panjang $20 \mathrm{~cm}$, lebar $2 \mathrm{~cm}$, dengan tebal spesimen $0,5 \mathrm{~cm}$ akan di letakan pada support span dengan panjang support span $100 \mathrm{~mm}$ kemudian spesimen akan di tekan kemudian Data yang didapat dari pengujian bending pada penelitian ini berupa gaya maksimal (Fmax), lalu dilakukan perhitungan kekuatan bending $(\sigma)$ tegangan. 
a. Hasil pengujian dengan variasi serat daun nanas $0^{\circ}$

Pada pengujian variasi arah serat $0^{\circ}$ di lakukan 5 pengujian spesimen dan menghasilkan nilai Max load paling tinggi adalah pada pengujian ke 4 atau D dengan nilai Max load $811.7352 \mathrm{~N}$ dan yang paling terendah pada pengujian ke 3 atau $\mathrm{C}$ dengan nilai 480.0821 N.

b. Hasil pengujian dengan variasi daun nanas $45^{\circ}$

Pada pengujian variasi arah serat $45^{\circ}$ di lakukan 5 pengujian spesimen dan menghasilkan nilai Max load paling tinggi adalah pada pengujian ke 4 atau D dengan nilai Max load $546.6128 \mathrm{~N}$ dan yang paling terendah pada pengujian ke 1 atau A dengan nilai $245.175 \mathrm{~N}$.

c. Hasil pengujin dengan variasi serat daun nans $90^{\circ}$

Pada pengujian variasi arah serat $90^{\circ}$ lakukan 5 pengujian spesimen dan menghasilkan nilai Max load paling tinggi adalah pada pengujian ke 2 atau B dengan nilai Max load $599.5019 \mathrm{~N}$ dan yang paling terendah pada pengujian ke 4 atau $\mathrm{D}$ dengan nilai 386.8763 N.

Dari pengujian bending di di atas yang telah dilakukan pada komposit Hybrid serat kaca dan serat alam daun nanas dengan variasi arah sudut $0^{\circ}, 45^{\circ}, 90^{\circ}$ dengan masing-masing variabel 5 spesimen maka di dapat tabel perbandingan maximal load seperti yang terdapat pada tabel 4.1 hal pengujian bending sebagi berikut

Tabel 1. Hasil Uji bending

\begin{tabular}{|c|c|c|c|c|}
\hline \multirow{2}{*}{ Spesimen } & \multicolumn{3}{|c|}{ Max load (N) } & \multirow{2}{*}{ Span $(\mathrm{mm})$} \\
\cline { 2 - 4 } & $0^{\circ}$ & $45^{\circ}$ & $90^{\circ}$ & \\
\hline 1 & 782.9418 & 245.175 & 510.1307 & 100 \\
\hline 2 & 527.7931 & 439.2457 & 599.5019 & 100 \\
\hline 3 & 480.0821 & 486.3978 & 531.2158 & 100 \\
\hline 4 & 811.7352 & 546.6128 & 386.8763 & 100 \\
\hline 5 & 637.7394 & 489.9871 & 488.7318 & 100 \\
\hline
\end{tabular}

Dari tabel di atas maka dapat di hitung kekuatan bending dengan rumus :

$$
\begin{array}{rlrl}
\sigma_{b} & =\frac{3 \mathrm{PL}}{2 b d^{2}} & & \text { Dengan : } \\
\sigma_{b} & =\frac{3 \times 782.9418 \times 100}{2 \times 20 \times 5^{2}} & & \mathrm{p}(\text { Beban })=782.9418(\mathrm{~N}) \\
\sigma_{b} & =234.8825535 \mathrm{Mpa} & & \mathrm{b}(\text { Panjang span })=100(\mathrm{~mm}) \\
& & \mathrm{d}(\text { Tebal Spesimen })=20(\mathrm{~mm})
\end{array}
$$

Dari perhitungan di atas maka didapatkan tabel perbandingan kekuatan bending dari masingmasing spesimen dan variasi seperti yang di sebagai berikut :

Tabel 2 Perbandingan Kekuatan Bending

\begin{tabular}{|c|c|c|c|c|}
\hline \multirow{2}{*}{ spesimen } & \multicolumn{3}{|c|}{ Kekuatan Bending $(\mathrm{MPa})$} & \multirow{2}{*}{ span $(\mathrm{mm})$} \\
\cline { 2 - 4 } & $0^{\circ}$ & $45^{\circ}$ & $90^{\circ}$ & \\
\hline 1 & 234.8826 & 73.5525 & 153.0392 & 100 \\
\hline 2 & 158.3379 & 131.7737 & 179.8506 & 100 \\
\hline 3 & 144.0246 & 145.9193 & 159.3647 & 100 \\
\hline 4 & 243.5206 & 163.9838 & 116.0629 & 100 \\
\hline 5 & 191.3218 & 146.9961 & 146.6196 & 100 \\
\hline rata rata & 194.4175 & 132.4451 & 150.9874 & 100 \\
\hline stand dev & 44.43898 & 34.84526 & 23.16393 & \\
\hline
\end{tabular}




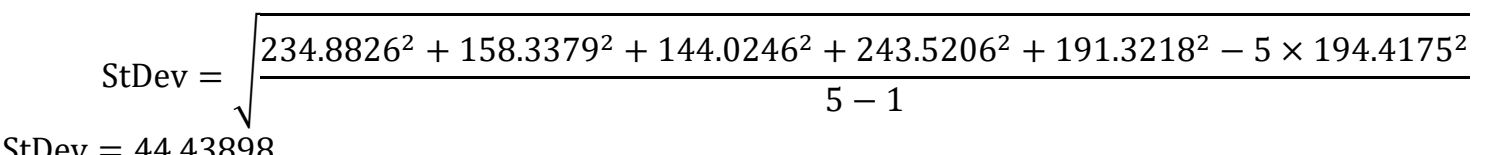

Dari hasil perhitungan kekuatan bending telah dilakukan maka di dapat nilai kekuatan bending paling tinggi pada komposit Hybrid serat kaca dan serat daun nanas variasi arah serat daun nanas adalah dengan arah sudut $0^{\circ}$ dengan nilai rata- rata kekuatan bendingnya 194,4175 dengan nilai standar deviasi 44,43898 kemudian variasi sudut $90^{\circ}$ dengan nilai rata rata kekuatan bending 150,9874 Mpa dengan standar deviasi 23.16393 dan yang paling rendah sudut $45^{\circ}$ dengan nilai rata-rata kekuatan bending 132,4451 Mpa dengan standar deviasi 23.16393

Dengan data tersebut juga diperoleh grafik hubungan antara kekuatan bending dengan variasi arah sudut serat daun nanas seperti terlihat dalam gambar grafik

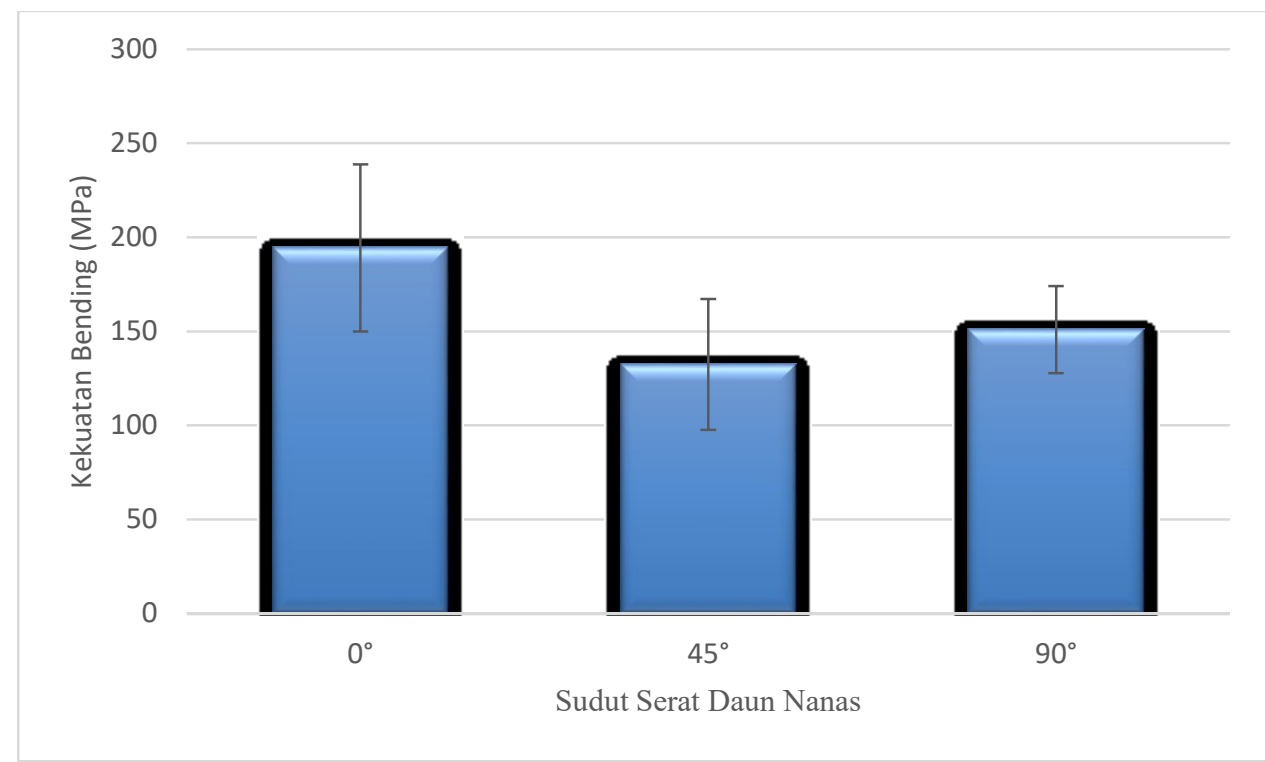

Gambar 1. Grafik kekuatan Bending Vs arah serat daun nanas

Berdasarkan uji bending yang telah dilakukan pada spesimen komposit Hybrid serat kaca dan serat daun nanas yang telah di lakukan dengan variasi sudut serat daun nanas. Maka didapatkan nilai kekuatan bending paling besar pada arah serat sudut nanas $0^{\circ}$, dimana dengan nilai rata- rata kekuatan bendingnya 194,4175 dengan nilai standar deviasi 44,43898. Hal ini dapat terjadi karena serat daun nanas dengan sudut $0^{\circ}$ merupakan sumbu longitunal searah dengan sumbu $x$, di mana sumbu longitudinal merupakan sumbu yang berlawanan arah dengan datangnya gaya vertikal yang di bebankan oleh mesin uji bending sehingga dapat menahan beban dengan sangat baik. Harga kekuatan pada arah sudut serat daun nanas $45^{\circ}$ dapat dikatakan merupakan sudut kritis karena merupakan sudut dengan kekuatan bending paling lemah pada komposit Hybrid serat kaca dan serat daun nanas ini dengan nilai 132,4451 Mpa dengan standar deviasi 23.16393 di bandingkan dengan sudut serat daun nanas $0^{\circ}$ dan $90^{\circ}$. Dalam perancangan komposit sudut orientasi kritis harus di hindari dan sudut tersebut karena dapat mengakibatkan dapat mengurangi keefektifan serat dalam beban. Penentuan sudut dalam desan komposit dapat di sesuaikan dengan arah datangnya pembebanan. 


\section{Kesimpulan}

Nilai kekuatan bending arah sudut 0 dengan nilai rata- rata kekuatan bendingnya 194,4175 dengan nilai standar deviasi 44,43898 kemudian variasi sudut 90 dengan nilai rata rata kekuatan bending 150,9874 Mpa dengan standar deviasi 23.16393 dan yang paling rendah sudut 45 dengan nilai rata-rata kekuatan bending 132,4451 Mpa dengan standar deviasi 23.16393. Kekuatan bending paling besar pada arah serat sudut nanas $0^{\circ}$ dan Harga kekuatan pada arah sudut $45^{\circ}$ dapat dikatakan merupakan sudut kritis karena merupakan sudut dengan kekuatan bending paling lemah.

\section{DAFTAR PUSTAKA}

[1] Fernanda Erick, 2015, Pengujian Mekanik Material Komposit Hybrid Dengan Penguat Serat Kelapa Dan Rami. Stta, Yogyakarta.

[2] David, Cripss. 2010. Manufacturing Guide And Tools, Http://Netcomposites.Com/Guide Tools/Guide,(Diakses 20:25, 29 Mei 2021).

[3] Diharjo, K., Dan Triyono, T., 1999. Buku Pegangan Kuliah Material Teknik, Universitas Sebelas Maret, Surakarta.

[4] Dwi, U. B. 2018. Pengaruh Variasi Anyaman Material Komposit Epoxy Berpenguat Bilahan Bambu Terhadap Kekuatan Bending. Skripsi. Semarang: Universitas Negeri Semarang.

[5] Lies Banowati, 2019, Analisis Perbandingan Kekuatan Tarik Komposit Hybrid Serat Daun Nanas - E-Glass / Epoxy Bakalite Epr 174 Dan Hybrid Serat Daun Nanas - EGlass / Vinyl Ester Repoxy R 802, Universitas Nurtanio Bandung, Bandung

[6] Mujiyono Dan Didik H, Pemanfaatan Serat Daun Nanas Sebagai Penguat Material Komposit, Skripsi, Program Sarjana Fakultas Teknik Uny, Yogyakarta, 2009

[7] Nurun Nayiroh. Teknologi Material Komposit.[Online]. Http://Nurun.Lecturer.UinMalang.Ac.Id/Wpcontent/Uploads/Sites/7/2013/03/Material-Komposit.Pdf.[17:03， 29 Mei 2021].

[8] Sari N. H, Sinarep, Taufan A., Yudhyadi I., (2011), "Ketahanan Bending Komposit Hybrid Serat Batang Kelapa/Serat Gelas Dengan Matrik Urea Formaldehyde”, Jurnal Ilmiah Teknik Mesin Vol. 5 No.1. April 2011

[9] Silvia Pratiwi, 2015, Pengaruh Varias Tebal Core Dan Fraksi Volume Terhadap Kekuatan Mekanik Komposit Sandwich Polyester Berpenguat Serat Daun Nanas (Ananas) Dengan Core Styrofoam, Universitas Jember, Jember.

[10] Utama, F. Y. Dan Zakiyya, H. 2016. Pengaruh Variasi Arah Serat Komposit Berpenguat Hibrida FiberHybrid Terhadap Kekuatan Tarik Dan Densitas Material Dalam Aplikasi Body Part Mobil. Mekanika. 15(2):60-69. 